\title{
La acción ciudadana transforma la casa-taller March en museo comunitario
}

La praxis de museo comunitario no es extendida en el mundo occidental ya que se ha desarrollado especialmente en América Latina. Sin embargo, la experiencia que presentamos se realiza en la casataller de la familia March en el barrio del Carmen en Valencia. Surgió a partir de los movimientos vecinales en defensa de las viviendas, contra las expropiaciones y la gentrificación. Ideas que se unieron a la lucha por el mantenimiento de uno de los pocos talleres artesanos de sus características que queda en la ciudad. El resultado es una experiencia ciudadana que mantiene activo el taller a través de actividades educativas, lúdicas, expositivas, de trabajo artesanal, generando un verdadero espacio vivo.

Josep Montesinos i Martínez | Dpto. Historia del Arte, Universitat de València

Url de la contribución <www.iaph.es/revistaph/index.php/revistaph/article/view/4518>

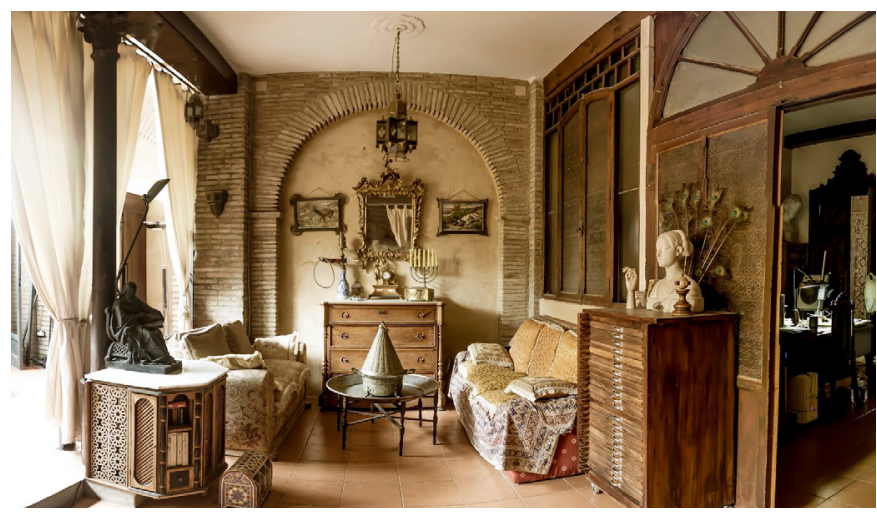

Zona de vivienda | fuente Casa-taller March, Hacia un Museo Comunitario, de todas las imágenes que ilustran esta contribución

La permanente evolución del concepto de museo, en perpetua crisis, ha ido produciendo muchas perspectivas y avances en todos los aspectos: desde la exposición, la narración, la conservación, la difusión, la gestión... Surgiendo modelos acordes a estos cambios como es el caso de los ecomuseos (VERINE, 2017: 37 y ss; RIVIÈRE, 1973: 75-80) y, como evolución de éste y más recientemente, el museo comunitario.

"Un museo comunitario es creado por la misma comunidad: es un museo 'de' la comunidad, no elaborado a su exterior 'para' la comunidad... Un museo comunitario es un espacio donde los integrantes de la comunidad construyen un autoconocimiento colectivo, propiciando la reflexión, la crítica y la creatividad. Fortalece la identi- dad, porque legitima la historia y los valores propios, proyectando la forma de vida de la comunidad hacia adentro y hacia fuera de ella. Fortalece la memoria que alimenta sus aspiraciones de futuro" (RED, 2018).

Este tipo de propuestas surge de la comunidad, con unos claros fines, especialmente educativos y culturales (MÉNDEZ LUGO, 2007), pero también reivindicativos, de memoria y mantenimiento de identidades. Los museos comunitarios se han desarrollado especialmente en el entorno latinoamericano donde las comunidades indígenas de Bolivia, Venezuela, Panamá, Costa Rica, Nicaragua, El Salvador, Guatemala, México, Colombia, Chile y Perú trabajan por su existencia, por su patrimonio cultural, por su memoria (RED, 2018).

Presentamos aquí un proyecto, una realidad, o más bien caminar, en la ciudad de Valencia: el taller artesano de la familia March. Es un 'obrador', es decir, conserva la antigua tipología de la casa junto al taller (casa+taIler). Este espacio artesanal se asienta en el barrio del Carmen, junto a la muralla de época andalusí (siglo XI). Excavaciones arqueológicas realizadas en el entorno han mostrado la existencia de actividades artesanales desde esa época islámica, en relación especialmente a una de las ramas de la acequia principal, la de Rovella, que aportaba agua a la ciudad medieval. Continuó como zona artesanal tras la conquista cristiana. El taller de la familia March existe desde finales del siglo XIX y, según 


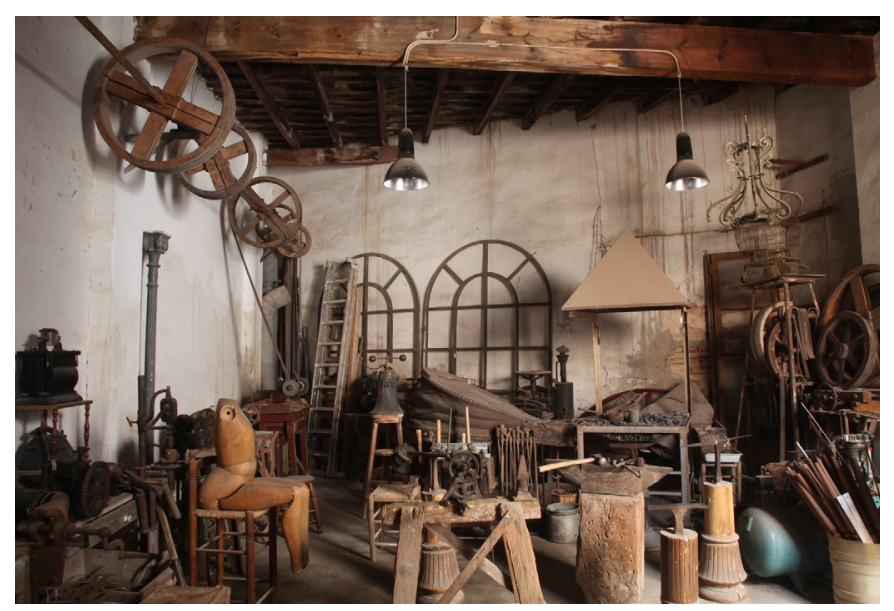

La fragua

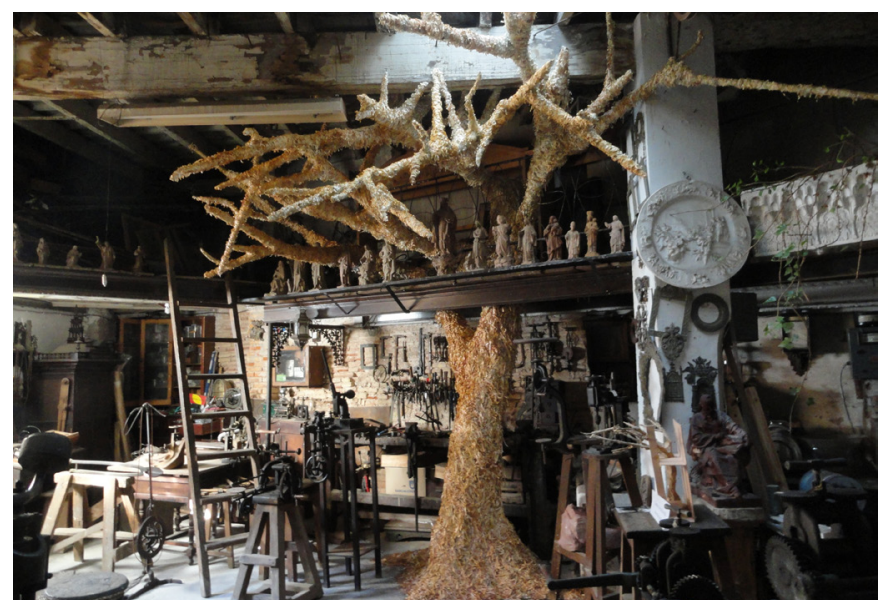

Obras escultóricas contemporáneas en un entorno artesanal

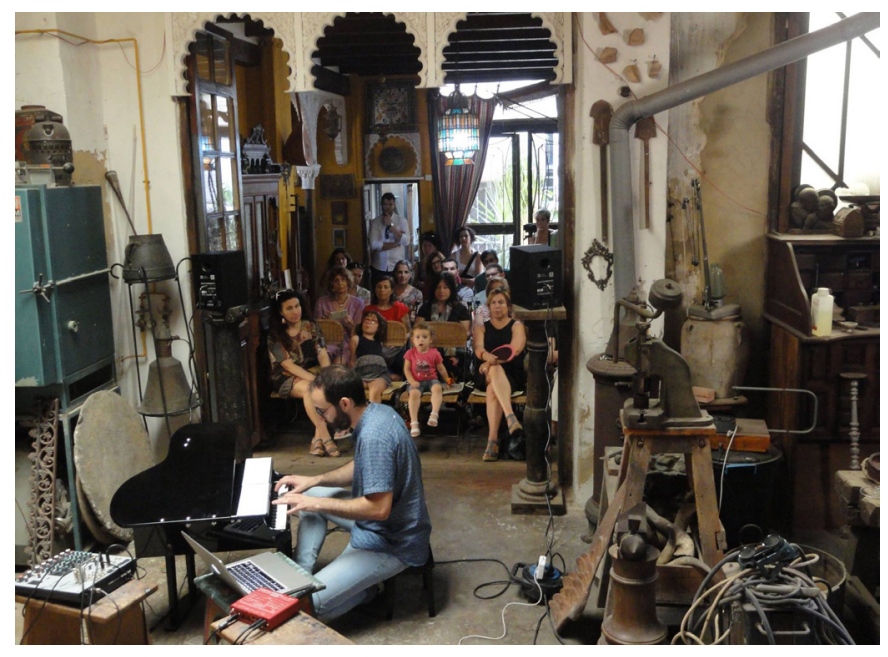

Concierto las épocas, se ha dedicado a distintas actividades tales como la seda, la imaginería, la orfebrería o el esmalte.

En el año 2002 la oficina de rehabilitación de la Ciutat Vella de Valencia (RIVA) proyectó para su ejecución un plan urbanístico con el fin de regenerar el barrio. Dicho proyecto suponía el derribo de una veintena de edificios, la expropiación de más de 50 familias y la desaparición de las actividades económicas que en ese momento existían.

Entre estas expropiaciones, el taller de la familia March, el único que quedaba en el entorno. A partir de ese momento, la ciudadanía se organiza y se une creando la Plataforma de la Muralla para la lucha contra dicho plan. En este sentido, hay que destacar que todos los proyectos urbanísticos ideados hasta el momento por los diversos gobiernos de la ciudad plantean el derribo del taller, para integrar dicho espacio en una plaza interior ajardinada, aún existiendo otras alternativas. En la plataforma mencionada se integró la casa-taller (MONTESINOS I MARTÍNEZ, 2019).

La lucha fue larga y al final se logró paralizar el plan y en 2016 se propuso otro consensuado del que nada se ha llevado a cabo. Desde el primer momento la reivindicación estuvo vinculada a acciones por la defensa del patrimonio, su conocimiento, difusión... Y la casa-taller ${ }^{1}$ fue uno de los elementos clave. De manera que, con el paso del tiempo, el movimiento derivó en una nueva organización con el leit motiv: Casa-taller March. Hacia un museo comunitario cuyos fines son:

$>$ La proyección de la casa-taller como verdadero museo comunitario.

> La protección y defensa de la casa-taller.

> La difusión de las actividades artesanales.

$>$ Acciones culturales y sociales en su entorno próximo y otros más alejados.

$>$ El estudio de la realidad artesana del pasado, las técnicas, producciones, economía, historia, sociedad... 
$>$ El estudio de la realidad artesana del presente y su proyección hacia el futuro.

$>$ Identificar, fortalecer y difundir el patrimonio cultural (tanto material como inmaterial) de nuestros barrios, como elemento clave en la identidad de la sociedad y como parte de su economía y calidad de vida.

Desde el principio de la lucha vecinal ${ }^{2}$ contra el mal llamado Plan de la Muralla, se llevaron a cabo diversas acciones, integradas ahora en esta perspectiva de museo en comunidad. Se realizan exposiciones (especialmente de productos artesanos y artísticos), actividades de técnicas artesanales, visitas tanto de centros educativos como de la ciudadanía en general... Y se participa en iniciativas de la ciudad como Ciutat Vella Oberta e Intramurs, conferencias, conciertos, cursos, mesas redondas, reuniones participativas...

Es evidente que nuestro planteamiento, o mejor, nuestra realidad, no coincide con los museos comunitarios de América. En ellos la base indígena y el entorno rural tienen una fuerte presencia. Por el contrario, nuestra realidad no se refiere a una base étnica, pero sí a unas formas de vida y trabajo que funcionaban hace años y que se están perdiendo (desde unos barrios más humanos, un uso del espacio público más social o un comercio de proximidad) en pos de una ciudad neoliberal, en palabras de David Harvey: "estamos concentrando nuestros esfuerzos y recursos hacia la construcción de ciudades para invertir en lugar de ciudades para vivir. La satisfacción humana se mide ahora en dinero" (Marti; Salazar, 2016). Otra diferencia respecto a los museos comunitarios de América es que estamos en un entorno urbano, con su complejidad y características.

Pero aunque los modelos no son los mismos que en América, las intenciones, los deseos y la filosofía son idénticos. Este camino nos lleva hacia procesos más participativos, creando un museo de abajo arriba.

En mi opinión el museo ya estaba allí, era y es una realidad palpable de la historia, del trabajo, de la memoria de una familia, de un grupo humano, de un barrio, de una sociedad. En este sentido es el museo el que ha encon- trado una comunidad y, con ello, ha dado voz a esa misma gente: "Museos que encuentran Comunidades. Comunidades que encuentran Voz" (FERNÁNDEZ MORENO, 2014).

\section{NOTAS}

\section{1. http://lamuralladelcarme.blogspot.com}

2. La Plataforma de la Muralla, que fue la base, junto al taller, del museo comunitario, está integrada por la ciudadanía y colectivos sociales del entorno: asociaciones de vecinos y asociaciones culturales.

\section{BIBLIOGRAFÍA}

- FERNÁNDEZ MORENO, A. (2014) el museo que se hace a sí mismo. Tesis doctoral inédita, Universidad de Granada. Disponible en línea <http://digibug.ugr.es/ bitstream/handle/10481/46431/26536365.pdf?sequence =1\&isAllowed=y> [Consulta: 05/12/2019]

- MARTI, M.; SALAZAR, M. (2016) Entrevista a David Harvey sobre gentrificación: "Habitat III tiene una posición neoliberal". En Centro de Derechos Económicos y Sociales [en línea] 10 de agosto de 2016 <http://cdes.org.ec/web/entrevista-a-davidharvey-sobre-gentrificacion-habitat-iii-tiene-una-posicionneoliberal/\#prettyPhoto> [Consulta: 05/12/2019]

- MÉNDEZ LUGO, R. A. (2007) Teoría y método de la nueva museología en México. Una experiencia de organización social a partir de la gestión cultural. Mus-A: Revista de los museos de Andalucía, n. ${ }^{\circ}$ 8, 2007, pp. 40-49

- MONTESINOS I MARTíNEZ, J. (2019) Ciudad, Patrimonio y Gentrificación. Hacia una casuística significativa con el mal llamado Plan de la Muralla. En FARINÓS, J. (dir.) Hacia una nueva inteligencia territorial en la Comunitat Valenciana. Aportes desde la Cátedra de Cultura Territorial Valenciana 2016-2017. València: CCTV/PUV, 2019, pp. 87-106

- RED de Museos Comunitarios de América [en línea] s.l: Museos Comunitarios de América <http://www.museos comunitarios.org/que-es> [Consulta: 05/2018]

- RIVIÈRE. G. H. (1973) Función del museo de ciencias humanas y sociales. Museum, 25 (1/2), 1973, pp.75-80

- VARINE, H. (DE) (2017) L'écomusée singulier et pluriel. Un témoignage sur cinquante ans de muséologie communautaire dans le monde. Paris: L'Harmattan, 2017 (Muséologies) 